\title{
Applied multifocus 3D microscopy
}

\author{
Thierry Zamofing, Heinz Hügli* \\ Institute of Microtechnology, University of Neuchâtel, CH-2000 Neuchâtel, Switzerland
}

\begin{abstract}
The depth from focus measurement principle relies on the detection of the optimal focusing distance for measuring the depth map of an object and finding its 3D shape. The principle is most effective at microscopic ranges where it is usually found implemented around a z-controlled microscope and sometimes named multifocus 3D microscopy. As such, the method competes with many other 3D measurement methods showing both advantages and disadvantages. Multifocus 3D microscopy is presented and compared to chromatic aberation, confocal microscopy, white light interferometry. Then, this paper discusses two applications of multifocus 3D microscopy for measuring wood respectively metallic parts in the sub-millimeter range. The first application aims at measuring the topography of wood samples for surface quality control. The wood samples surface topography is evaluated with data obtained from both confocal microscopy and multifocus 3D microscopy. The profiles and a standard roughness factor are compared. The second application concerns the measurement of burrs on metallic parts. Possibilities and limits of multifocus 3D microscopy are presented and discussed.
\end{abstract}

Keywords: Visual inspection, depth from focus, multifocus 3D, micrometric 3D metrology, wood topography, burr measurement

\section{INTRODUCTION}

Depth from focus designates a method by which, depth from a scene is recovered by measuring the contrast change in a series of images of the scene focused at several depths. Each point of the scene is given the depth associated to the image with the highest contrast at that point. The method is proposed in the mid- $80^{[1]}$. The depth accuracy, intrinsically bound to the depth of field, may differ strongly in various configurations. Because it operates with a reduced depth of field, microscopy is best suited for its application. A fully automated shape from focus microscopic system has been implemented in the early $90^{[2]}$.

The location with highest contrast is commonly detected by maximum sharpness detection in a full series of images but can also be obtained by sharpness estimation from only of few images ${ }^{[3]}{ }^{[15]}$ in which case the method is usually named depth from defocus. This paper deals with the first approach using a full series of images in the context of microscopy and names it multifocus 3D microscopy to avoid confusion with other variant methods.

Detecting the contrast peaks is a quite computer intensive task. Many contrast functions have been studied ${ }^{[5][16]}$ to provide the best possible focus estimate at lowest computational costs. Traditionally, multifocus depth computation performed on general purpose computer remained somehow slow ${ }^{[8]}$. The paper shows that today computer performances tend to suppress this drawback and also lead this technique to new fields of application.

This paper analyses the performance of multifocus 3D microscopy and discusses its application for measuring wood respectively metallic parts in the sub-millimeter range. The first application aims at measuring the topography of wood samples for surface quality control. The wood samples surface topography is evaluated with data obtained from both confocal microscopy and multifocus 3D microscopy. A comparison based on profiles and a standard roughness factor is presented. The second application concerns the measurement of burrs on metallic parts. 


\section{MULTIFOCUS 3D MICROSCOPY}

\subsection{Principle}

A series of images is recorded by a microscope with varying object to lens distance z (see figure 1). Multifocus 3D microscopy designates a method by which, depth from a scene is recovered by analyzing the series of images. During analysis each image location is processed and the image with the best local contrast is found. The depth at each location is then simply the $\mathrm{z}$ value associated to the found image.

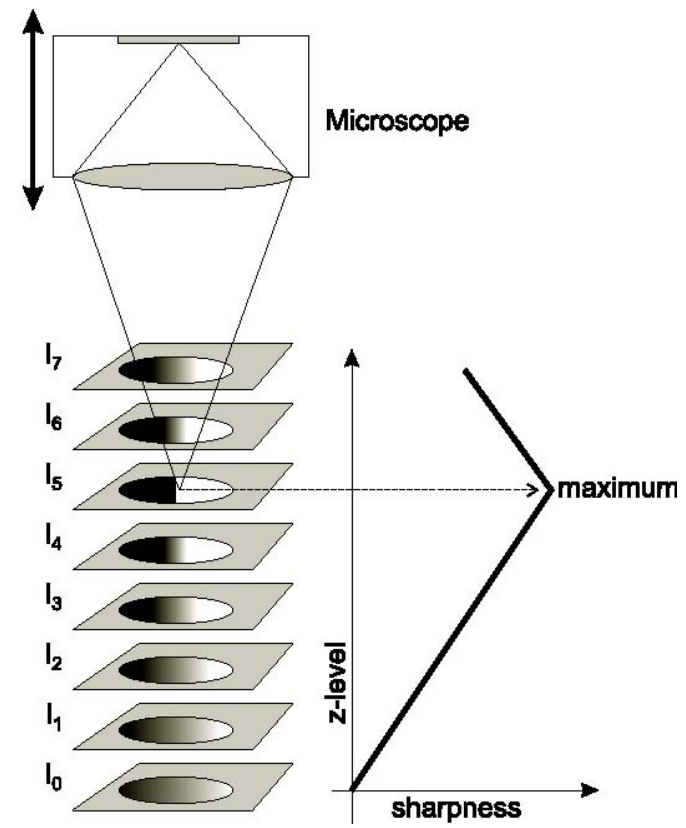

Figure 1. Multifocus 3D microscopy

Given a series of images $I_{1} \ldots I_{n}$ taken at respective object to lens distances $z_{1} \ldots z_{n}$, the method computes first the respective sharpness images by means of the sharpness operator $\mathrm{S}()$ :

$$
\mathrm{s}_{\mathrm{i}}(\mathrm{x}, \mathrm{y})=\mathrm{S}\left(\mathrm{I}_{\mathrm{i}}(\mathrm{x}, \mathrm{y})\right)
$$

and then for each point $(\mathrm{x}, \mathrm{y})$ in these images, it finds the image index with the maximal sharpness:

$$
\hat{\mathrm{i}}(\mathrm{x}, \mathrm{y})=\operatorname{argmax}_{\mathrm{i}} \mathrm{s}_{\mathrm{i}}(\mathrm{x}, \mathrm{y})
$$

The depth of the scene at each point $(\mathrm{x}, \mathrm{y})$ is then simply the associated $\mathrm{z}$-value

$$
\mathrm{Z}(\mathrm{x}, \mathrm{y})=\mathrm{z}_{\hat{1}}(\mathrm{x}, \mathrm{y})
$$

\subsection{Depth of field}

When located at the optimal focusing distance, a point of the object is mapped ideally as a point in the image plane, but a similar point located at a different depth will be imaged ideally at another image plane, producing an unsharp point in the real image, shown as spot of diameter $u_{b}$ in figure 2 below. 


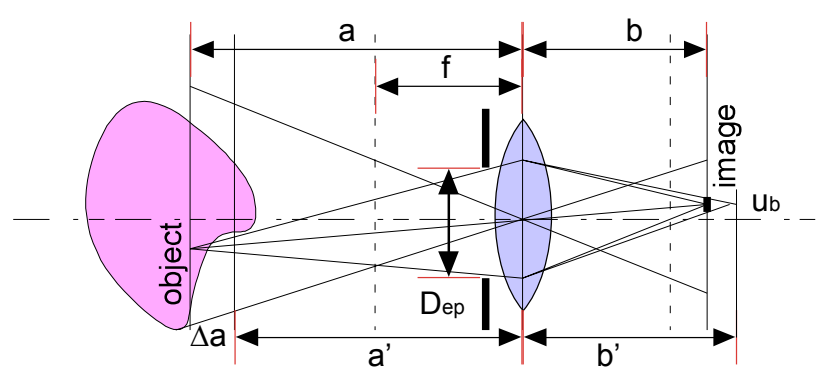

Figure 2. Unsharpness $u_{\mathrm{b}}$ resulting from depth shift $\Delta \mathrm{a}$

The relation between the new depth $a^{\prime}$ and the diameter $u_{b}$ of the spot derives from simple geometry ${ }^{[4]}$. The relation which expresses a' as a function of microscope magnification $\beta$ is:

$$
a^{\prime}=\frac{f(1+\beta)}{\beta+\frac{u_{b}}{D_{e p}}} \quad \text { where } \beta=\frac{b}{a}
$$

The depth of field for a given configuration is defined as the range of object distances where focusing is not worse than $\mathrm{u}_{\mathrm{b}}$, its value is found by the difference of distances $\mathrm{a}^{\prime \prime}$ and $\mathrm{a}^{\prime}$ behind and in front of a which produce the spot size $\mathrm{u}_{\mathrm{b}}$, formally:

$$
\Delta a=a^{\prime \prime}-a^{\prime}=\frac{f(1+\beta)}{\beta-\frac{u_{b}}{D_{e p}}}-\frac{f(1+\beta)}{\beta+\frac{u_{b}}{D_{e p}}}=\frac{2 f(1+\beta) \frac{u_{b}}{D_{e p}}}{\beta^{2}-\frac{u_{b}{ }^{2}}{D_{e p}{ }^{2}}} \approx \frac{(1+\beta)}{\beta^{2}} 2 \frac{u_{b} f}{D_{e p}} \approx \frac{(1+\beta)}{\beta^{2}} 2 u_{b}
$$

where the successive approximations hold for relative limited unsharpness $u_{b}<<D_{\text {ep }}$, and a microscope with numerical aperture near 1. This depth of field can also be understood as the accuracy of depth measurement, under the assumption of the detection capability of a spot of size $u_{\mathrm{b}}$. Figure 4 plots this depth of field or accuracy function. Curve number 1 corresponds to a spot size of $u_{b}=20 \mu \mathrm{m}$ and curve number 2 corresponds to a spot size of $u_{b}=10 \mu \mathrm{m}$.

The fact that $\Delta \mathrm{a}$ is intrinsically bound to magnification $\beta$ by above rule means that low magnification goes with low accuracy and high magnification is required for higher accuracy. Given that the object field of view decreases with higher magnification, this means also that high accuracy is only possible with a reduced field of view.

\subsection{System description}

This section describes the multifocus 3D microscope that was developed and used in following applications. It is composed of a conventional optical microscope, $\mathrm{x}, \mathrm{y}$ and $\mathrm{z}$ displacement stages, a video camera and a personal computer that controls the whole.

A first configuration uses the DMLA industry microscope ${ }^{[10]}$ which is fully automated and comes equipped with controller, $\mathrm{x}, \mathrm{y}$ and z-motors and a joystick. The used camera is a 1 Mpixel monochrome Pulnix Tm1001 with a 1" $(9.1 \mathrm{~mm} \times 9.1 \mathrm{~mm})$ chip, squared pixels and a pixel pitch of $\mathrm{p}=9.0 \mu \mathrm{m}$. An alternative configuration suited for lesser magnification is composed of the Leica MZ12 microscope, an x,y-table and a controller from Merzhäuser. 

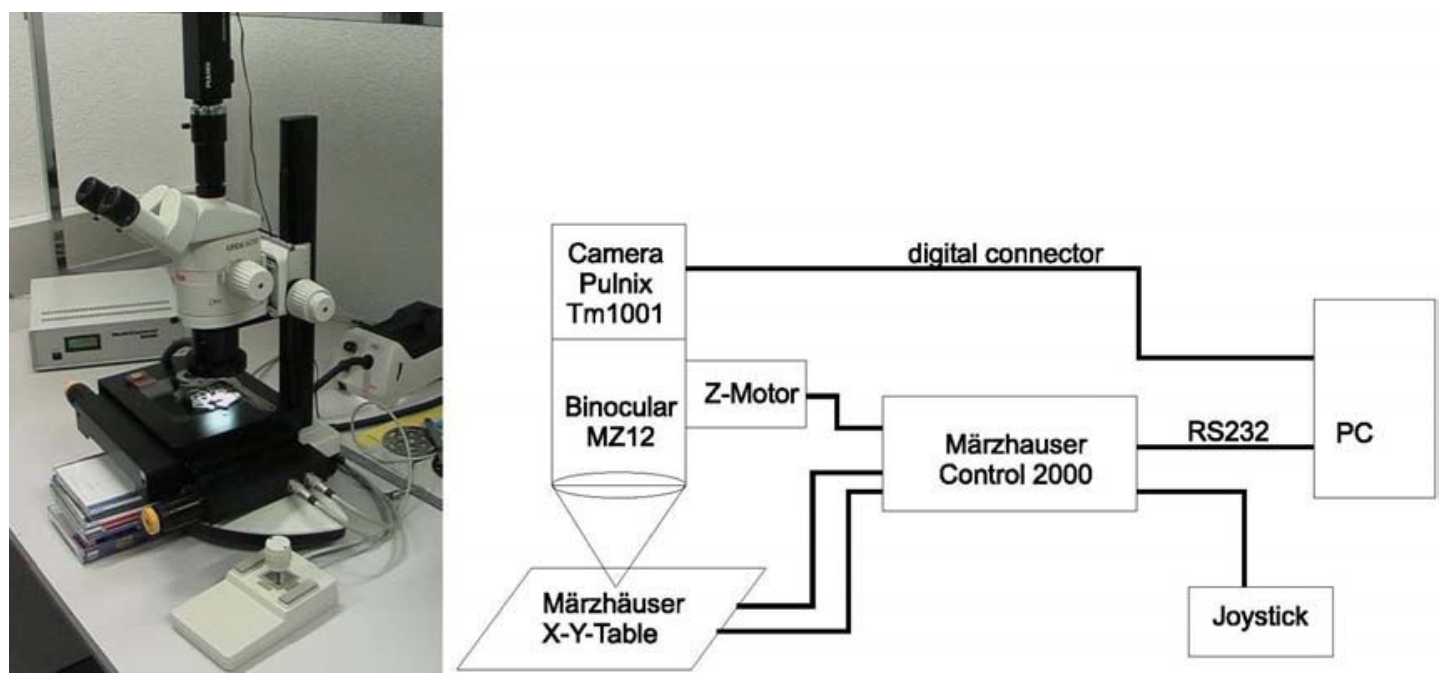

Figure 3: System overview MZ12

Video images are acquired currently at a rate of $7.5 \mathrm{~Hz}$. Image processing is on the fly. Among the large palette of available sharpness operators ${ }^{[5][16]}$ the system uses either the Laplacian operator:

$$
S_{\text {lap }}(I)=\nabla^{2} I(x, y)=|I * K| \quad \text { with for instance } K=\left(\begin{array}{ccc}
1 & 2 & 1 \\
2 & -12 & 2 \\
1 & 2 & 1
\end{array}\right)
$$

or the grey level variance operator with a variable neighborhood $\mathrm{B}_{\mathrm{x}} \times \mathrm{B}_{\mathrm{y}}$ of size $\mathrm{w} \times \mathrm{w}$ ranging from $3 \times 3$ up to $21 \times 21$ defined as:

$$
S_{\mathrm{var}}(I)=\frac{1}{w^{2}} \sum_{x \in \mathrm{Bx} y \in \mathrm{By}} \sum_{1}|I(x, y)-\mu|^{2} \quad \text { with } \quad \mu=\frac{1}{w^{2}} \sum_{x \in \mathrm{B} x} \sum_{y \in \mathrm{By}} I(x, y)
$$

Fast sharpness computation is obtained as follows. Given the fact that Laplacian kernels can be approximated with a difference of two Gaussians and the nice property of Gaussians to be separable, sharpness original computational complexity $\mathrm{O}\left(\mathrm{w}^{2}\right)$ can be reduced to $\mathrm{O}(\mathrm{w})^{[6][7]}$ and the computation cost can be reduced in the same proportion.

Fast computation of the grey level variance operator is also possible with fast box filtering and image squaring functions. Indeed, given the constant box filter $\mathrm{H}$ of size $\mathrm{w} \times \mathrm{w}$, the averaging operations can be replaced by convolutions with $\mathrm{H}$ and above definition of variance can be rewritten:

$$
S_{\text {var }}(I)=I^{2} * H-(I * H)^{2}
$$

Because the box filter is separable and all its coefficients have the same value, it can be implemented in a way to be nearly independent from its width $\mathrm{w}$. Such fast box filtering together with a fast image squaring function permit a real efficient computation of this sharpness operators.

\begin{tabular}{|c|c|c|}
\hline & MIL & OpenCV \\
\hline 3x3 Laplace & $58 \mathrm{~ms}$ & $40 \mathrm{~ms}$ \\
\hline 5x5 Laplace & $69 \mathrm{~ms}$ & $64 \mathrm{~ms}$ \\
\hline 21x21 Laplace & $450 \mathrm{~ms}$ & $150 \mathrm{~ms}$ \\
\hline 21x21 Variance & - & $56 \mathrm{~ms}$ \\
\hline
\end{tabular}

Table 1: Compared performance for sharpness computation 
To reach highest performance, the two sharpness operators were implemented with the two libraries MIL ${ }^{[17]}$ and OpenCV ${ }^{[18]}$ which are optimally designed for Pentium architectures. Table 1 reports the execution times for computing the sharpness of a $1 \mathrm{M}$ pixel image on a $1.8 \mathrm{GHz}$ Pentium processor by using dedicated library IPL ${ }^{[19]}$. Best performance is obtained for variance computation with OpenCV, the maximum processing time of $56 \mathrm{~ms}$ permitting real time acquisitions of $1 \mathrm{M}$ pixel images at frequencies above $20 \mathrm{~Hz}$ on current processors.

Notice that the rate of range images $f_{z}$ is bound to the just mentionned image rate $f_{i}$ but also to the number of slices $N_{s}$ by

$$
\mathrm{f}_{\mathrm{z}}=\mathrm{f}_{\mathrm{i}} / \mathrm{N}_{\mathrm{s}}
$$

and that quite higher image rates are possible at the expense of spatial resolution.

\section{COMPARISON WITH OTHER SYSTEMS}

There is a very large variety of $3 \mathrm{D}$ measurement methods. In the sub-millimeter range, methods of interest include mechanical scanning, electrical gage, functional testing, metallographic section, eye control, optical comparators, shadow length, laser triangulation, white light interferometry, laser interferometry, AFM, capacitive gage, confocal microscopy. Among methods of interest for non contact, fast, near micrometer range measuring methods we retain four methods for further analysis and comparison:

- multifocus $3 \mathrm{~d}$ microscopy

- chromatic abberation

- $\quad$ confocal microscopy

- white light interferometry

Chromatic aberration is a method based on a different refraction angle for each wavelength of light. White light is refracted in a way through an optical system lens so that each wavelength has a different focal distance. The surface reflects the light with a peak in its frequency spectrum. The reflected light is measured with a spectrometer and the peak frequency indicated the $\mathrm{z}$ position of the measured point.

Confocal microscopy: With this method a laser light beam is expanded and then focused to a small spot by an objective lens onto the probe. The reflected light is captured by the same objective and focused onto a photodetector via a mirror. A confocal aperture (pinhole) is placed in front of the photodetector, such that only the light reflected by the probe that is in the focal plane can pass trough. This technique is able to perform 3D topography acquisition with a submicron resolution.

White light interferometry: The white light interferometer is in principle a Michelson interferometer with a broad-band light source and a CCD camera as a detector. In this technique a pattern of bright and dark lines (fringes) result from an optical path difference between a reference and a sample beam. Incoming light is split inside an interferometer, one beam going to an internal reference surface and the other to the sample. After reflection, the beams recombine inside the interferometer, undergoing constructive and destructive interference and producing the light and dark fringe pattern. White light or interferometers have been used to perform 3D topography acquisition with a submicron resolution.

Table 2 compares multifocus 3D microscopy with the 3 other methods.

Regarding Z-accuracy, chromatic aberration, confocal microscopy and white light interferometer have all a very high zaccuracy. The z-accuracy and the z-measurement range of the chromatic aberration systems are defined with the used sensor. There exists different sensors, to cover 3 ranges from a few millimeters up to a few centimeters. But higher $z$ measurement range results in a lower $\mathrm{z}$ accuracy. The confocal microscope can vary the $\mathrm{z}$ accuracy with the pinhole size. Bigger pinhole results in more speed but less accuracy. Compared to these 3 systems, multifocus 3D microscopy has a low $\mathrm{z}$ resolution. Note that the multifocus $3 \mathrm{D}$ microscopy has also the already mentionnel disadvantage that the field of view is linked to the z-accuracy. 
Concerning price, the confocal microscope and the white light microscope are the most expensive measurement systems because they are more complex and they use not state of the art components. The chromatic aberration system is cheaper than those because the optic is not so complex. The main difference between a simple microscope and a multifocus 3D microscopy system is in fact just software. A multifocus system consists of an ordinary microscope with a camera a controller and a computer without any additional dedicated hardware. Therefore this system is the cheapest of all. This is one of the main advantages compared to its competitive systems.

\begin{tabular}{|c|c|c|c|c|}
\hline method & $\begin{array}{l}\text { multifocus 3d } \\
\text { microscopy }\end{array}$ & $\begin{array}{l}\text { chromatic } \\
\text { abberation }\end{array}$ & confocal microscopy & $\begin{array}{c}\text { white light } \\
\text { interferometry }\end{array}$ \\
\hline z-accuracy & $\begin{array}{c}2 \mu \mathrm{m}(\text { with } \\
\text { FOV } 1000 \mu \mathrm{m} x \\
1000 \mu \mathrm{m})\end{array}$ & $\begin{array}{l}>0.01 \mu \mathrm{m} \text { (depends } \\
\text { on used sensor) }\end{array}$ & $\begin{array}{c}\text { down to } 0.01 \mu \mathrm{m} \\
\text { (depends on pinhole } \\
\text { diameter) }\end{array}$ & $0.01 \mu \mathrm{m}$ \\
\hline $\begin{array}{l}\text { speed as } \\
\text { specified }\end{array}$ & $\begin{array}{c}3-5 \mathrm{fps} \\
(1024 \times 1024) \\
\text { effective } \\
\text { resolution } \approx \\
512 \times 512)\end{array}$ & $\begin{array}{l}\text { up to } 1000 \text { points } / \mathrm{s} \\
\text { typical } 300 \text { points } / \mathrm{s}\end{array}$ & $\begin{array}{c}4000 \text { lines/sec (Leica) } \\
10 \mathrm{fps}(640 \times 512) \\
\text { (Leica) }\end{array}$ & $\begin{array}{c}2,4 \mu \mathrm{m} / \mathrm{s}-12 \\
\mu \mathrm{m} / \mathrm{s} \text { (atos) up to } \\
10.5 \mu \mathrm{m} / \mathrm{s} \\
(640 \mathrm{x} 480) \\
(\text { Zygo })\end{array}$ \\
\hline $\begin{array}{c}\text { speed } \\
\text { example: } \\
512 \times 512 \text { pix } \\
200 \mu \mathrm{m} \\
\end{array}$ & $3-5 s$ & $500-1000 \mathrm{~s}$ & $3-5 \mathrm{~s}$ & $15-25 \mathrm{~s}$ \\
\hline approx. price & $40 \mathrm{k} \$$ & $60 \mathrm{k} \$$ & $70 \mathrm{k} \$$ & $70 \mathrm{k} \$$ \\
\hline $\begin{array}{l}\text { advantage } \\
\text { disadv. }\end{array}$ & $\begin{array}{c}+ \text { cheap }+ \text { simple } \\
\text {-FOV-accuracy } \\
\text { are coupled - } \\
\text { accuracy } \\
\text { depends of } \\
\text { material } \\
\text { structure }\end{array}$ & $\begin{array}{l}+ \text { precise }+ \text { robust } \\
\text { for steep slopes - } \\
\text { very slow }\end{array}$ & $\begin{array}{l}+ \text { fast }+ \text { precise } \\
+ \text { pinhole size can vary } \\
\text { the response depth - } \\
\text { expensive }\end{array}$ & $\begin{array}{c}\text { +medium fast } \\
\text { + precise - } \\
\text { expensive - } \\
\text { interferences } \\
\text { pattern have fix } \\
\text { depth }\end{array}$ \\
\hline
\end{tabular}

Table 2: Comparison of four 3D measurement methods

Speed is not directly comparable. To make an objective speed comparison, the time to scan a 3D region with a height of $200 \mu \mathrm{m}$ and a resolution of $512 \times 512$ pixel has been compared. The chromatic aberration system is very slow, because the sensor must scan the surface with a mechanical $x-y$ displacement and the spectroscope to measure the peak is rather slow. White light interferometry and multifocus 3D microscopy must both grab an image with a camera at different $\mathrm{z}$ levels and therefore their speed is similar. The first confocal microscope had either to move the microscope or the probe mechanically. Therefore this first generation was quite slow. But nowadays the confocal systems deflect the laser with optical systems and therefore their speed is high and competitive with multifocus 3D microscopy and white light interferometry.

\section{EXPERIMENTS}

\subsection{Accuracy}

A series of experiments was performed in order to evaluate the accuracy in real scenes. The selected four objects (larger ball, smaller ball, larger needle1, smaller needle2) are metallic and offer sufficient surface contrast. They have the simple shape of either a sphere or a cylinder, a feature which permits to derive the measurement error by the difference between measurement and a simple model.

Table 3 below reports for each part the resulting rms error together with the number of image slices used, the z-range covered by the acquisition, the type of microscope and its effective magnification. 


\begin{tabular}{|c|c|c|c|c|c|}
\hline Objects & $\begin{array}{c}\text { no of } \\
\text { slices }\end{array}$ & $\begin{array}{c}\text { z range } \\
{[\mu \mathrm{m}]}\end{array}$ & system & magnification & $\sigma[\mu \mathrm{m}]$ \\
\hline ball $1 \varnothing=10 \mathrm{~mm}$ & 32 & 261.7 & MZ12 & 6.3 & 4.81 \\
ball $2 \varnothing=8 \mathrm{~mm}$ & 32 & 229.8 & MZ12 & 10 & 5.92 \\
needle $2 \varnothing=0.8 \mathrm{~mm}$ & 32 & 350.4 & DMLA 10 x & 6.28 & 6.88 \\
needle $1 \varnothing=0.5 \mathrm{~mm}$ & 64 & 66.8 & DMLA 50 x & 31 & 1.95 \\
\hline
\end{tabular}

Table 3: Measurements of four parts

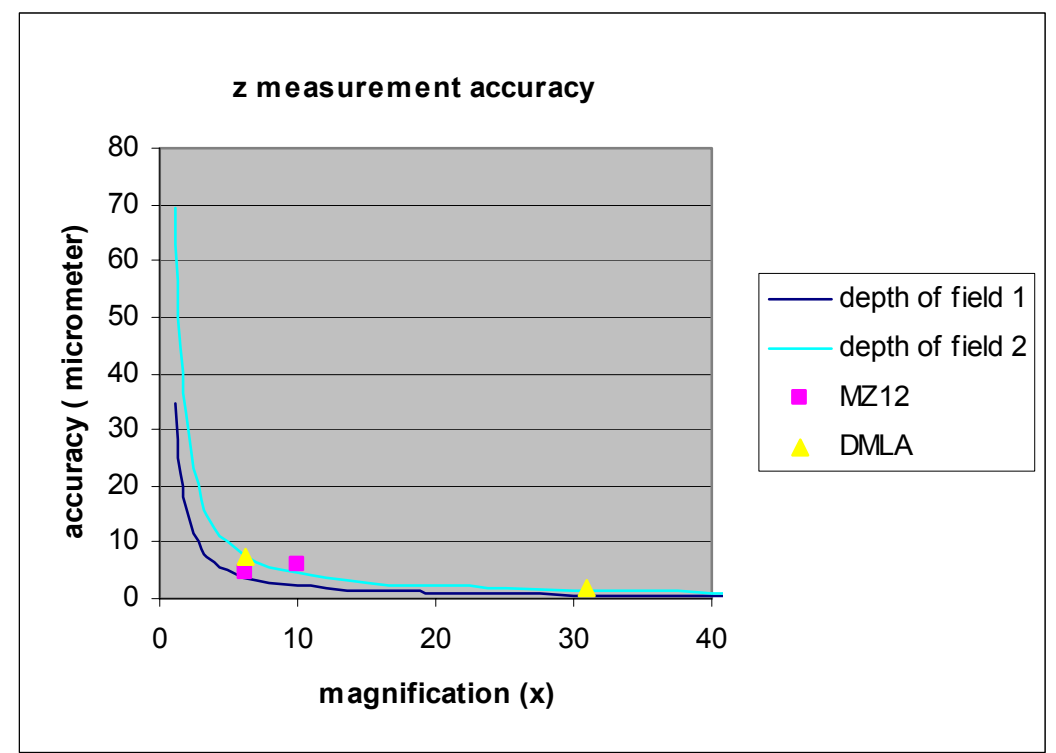

Figure 4: Depth accuracy and measurements as a function of magnification

Above measurements are reported in the accuracy versus magnification plot of figure 4 where a comparison with the theoretical performance can be done. The measurements lie between the depth of field curve 1 and 2 described earlier for a spot size $u_{b}=20 \mu \mathrm{m}$, respectively $u_{b}=10 \mu \mathrm{m}$. Considering the camera in use, this corresponds to approximately a spot size of $\mathrm{u}_{\mathrm{b}} / \mathrm{p}$ of two to one pixels in the image.

\subsection{Comparing with chromatic aberation}

Multifocus 3D microscopy is compared here with chromatic aberation by reporting a simple measurement of the same part by two techniques. Figure 5 shows a metallic part that was measured once with a chromatic aberation system (a) and once with the multifocus 3D microscope previously described (b).

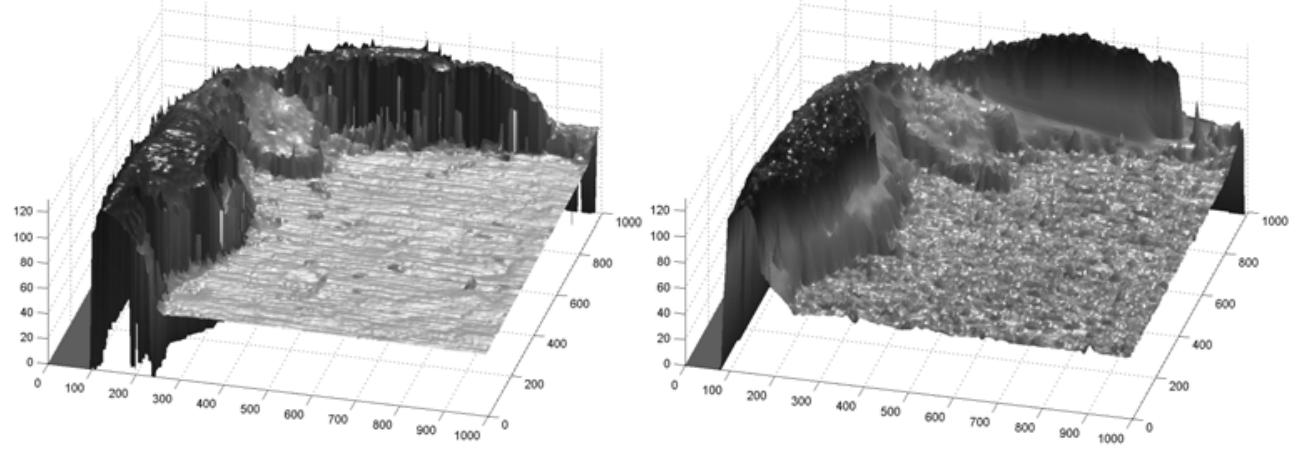

(a) Range map by chromatic aberration (b) Range map by multifocus 3D microscopy

Figure 5: Comparing measurements by different techniques 
The field of view is $1000 \mu \mathrm{m} \times 1000 \mu \mathrm{m} \times 120 \mu \mathrm{m}$. The resolution of the chromatic aberation image is $200 \times 200$. Multifocus 3D microscopy was performed with the DMLA using objective $10 \times$ and recording 32 slices. The resulting depth image of size $997 \times 1016$ was down sampled to the same $200 \times 200$ resolution for performing the comparison. After best matching of the two images, a difference image was computed and the rms value was evaluated in two distinct areas. In a first rather flat area, the rms is $1.28 \mu \mathrm{m}$. In a second area with more activity, the rms is $4.34 \mu \mathrm{m}$. Other comparisons with optical microscopy showed a better match with the chromatic aberation which clearly has less noise. Most part of the error comes back to multifocus 3D microscopy. Above errors fit also rather well in previous accuracy estimations and show how a practical setup performs on real parts.

\section{WOOD SURFACE MEASUREMENT}

This section reports the application of multifocus 3D microscopy to wood surface measurements. The considered task consists in the determination of the surface quality of processed wooden parts with respect to surface roughness. Wood surface roughness analysis is useful wherever parts must be qualified with respect to wood origin or a processing step like sanding for instance. In a series of experiments, wooden test samples were measured both by multifocus 3D microscopy and by confocal microscopy.

(a) maple

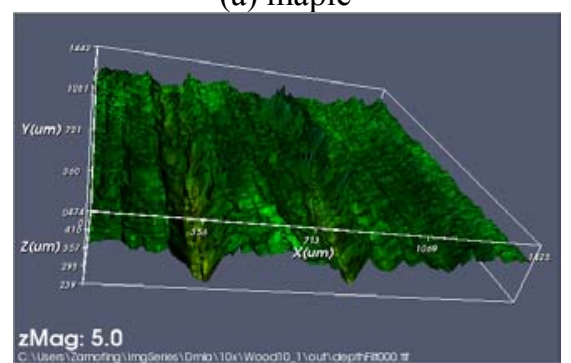

(b) oak

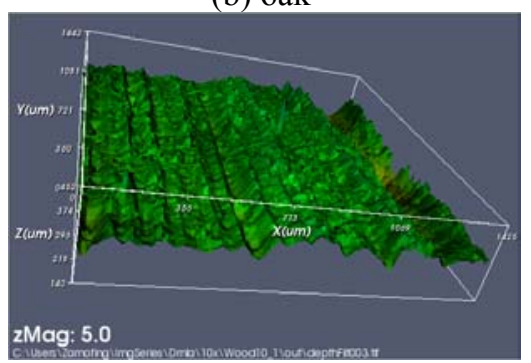

(c) flake-board

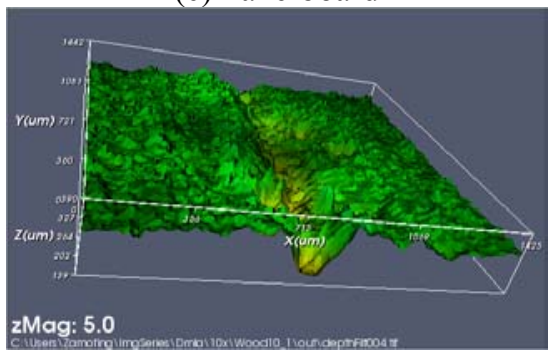

(1) Depth maps from multifocus 3D microscopy
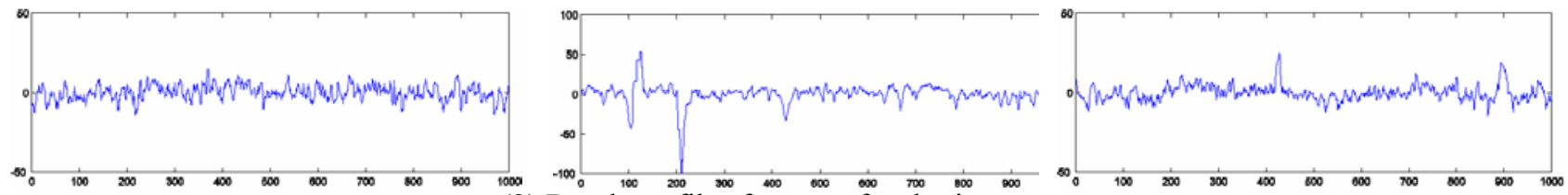

(2) Depth profiles from confocal microscopy
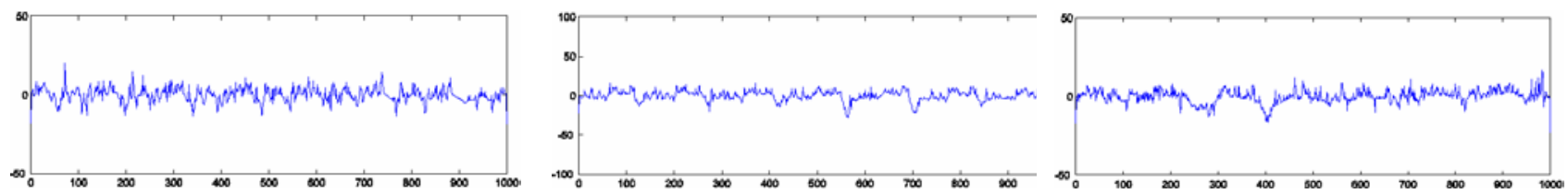

(3) Depth profiles from multifocus 3D microscopy

Figure 6: Measurements of wood samples

According to a classical procedure, wood samples are measured by confocal microscopy and depth profiles are analyzed. The sampling interval is $10 \mu \mathrm{m}$ typically, and a profile of 1000 samples covers thus $10 \mathrm{~mm}$. To determine the surface quality, many standard roughness metrics are available like: DIN 4771: $R_{t}$; DIN 4762: $R_{a}, R$; DIN 4762: $R_{s k}$, $\mathrm{R}_{\mathrm{ku}}$ and many others.

In a preliminary study, we explored the feasibility of wood surface roughness analysis by multifocal 3D microscopy. Wood samples already measured by confocal microscopy were again measured by multifocal 3D microscopy. Figure 6 
(1) shows the obtained depth maps for three samples of different woods: (a) maple, (b) oak and (c) flake-board. For sufficient accuracy a configuration with sufficient magnification is chosen: the DMLA 10x . Given the effective magnification of $\beta=6.28$ and the chip pixel size of $p=9.1 \mu \mathrm{m}$, the object field of view is $144 \mu \mathrm{m} \times 144 \mu \mathrm{m}$ with the 1 Mpixel camera. Note that above mentionned link between accuracy $\Delta \mathrm{a}$ and magnification $\beta$ can be disadvantageous in this application because of the related limitation of the object field of view.

The measurement by both methods could not be compared directly in absence of a precise registration procedure. The comparison performed so far consists in a visual comparison of surface profiles. Figure 6 compares the profiles of the three kinds of wood obtained first by confocal microscopy (2) and then by multifocus 3D microscopy (3). Despite the non-alignement, the profiles reveal a true similarity of the kind of measurements and suggest that later method could be applied as well. In addition, roughness measurement were performed on the different kinds of wood and showed following $R_{k}$ values for confocal versus multifocus $3 \mathrm{D}$ microscopy: $11.4 \mu \mathrm{m}$ versus $11.2 \mu \mathrm{m}$ for maple; $15.2 \mu \mathrm{m}$ versus $18.8 \mu \mathrm{m}$ for oak and $11.6 \mu \mathrm{m}$ versus $9.1 \mu \mathrm{m}$ for flake-board. Although not fully conclusive, these results suggest a real potential for an alternative wood analysis.

\section{METAL BURR MEASUREMENTS}

This section reports the application of multifocus 3D microscopy to metallic burr measurements. Burrs are a nuisance that almost any tool generate while working on a component. Any deviation of the component from its nominal (i.e. CAD) geometry could be considered as a burr. The smallest burrs of interest, though, seem to have a minimum height of about $5 \mu \mathrm{m}$ and are designed as micro burrs ${ }^{[9]}$, larger burrs can be as high as $1 \mathrm{~mm}$. Noticeable burrs are often located along the discontinuities (i.e. edges) of the component. Burrs are often irregular and appear as fractured and rough surfaces. Given the real interest to measure the burr height, width, angle at one or few locations of the component, sometimes even to measure the full component, multifocus 3D microscopy was applied forl range map acquisition.

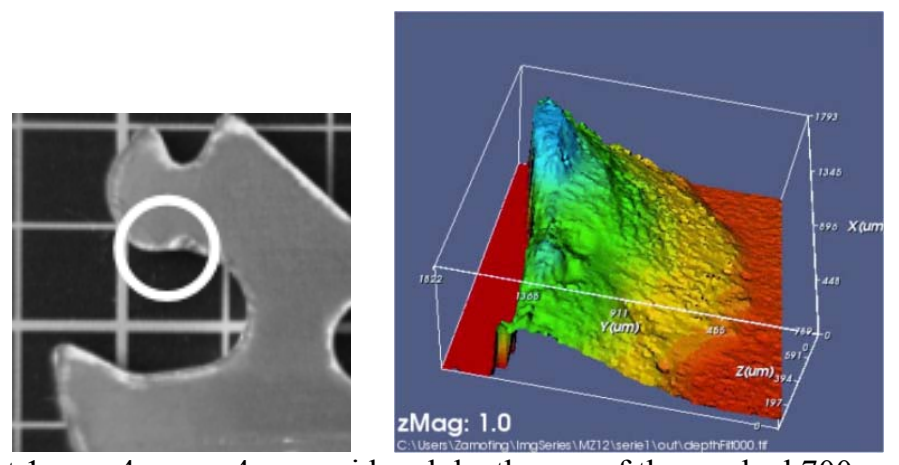

(a) Part 1 on a $4 \mathrm{~mm} \times 4 \mathrm{~mm}$ grid and depth map of the marked $700 \mu \mathrm{m}$ burr
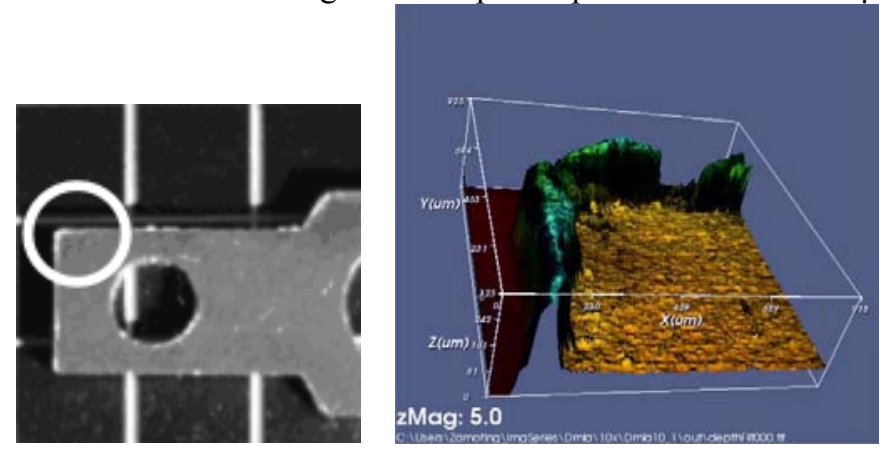

(b) Part 2 on a $4 \mathrm{~mm} \times 4 \mathrm{~mm}$ grid and depth map of the marked $50 \mu \mathrm{m}$ burr

Figure 7: Measurements of stamping burrs 


\subsection{Examples of Typical Measured Parts}

Multifocus 3D microscopy was extensively used for the measurement of burrs of various kind and dimensions. Typical examples of measured burrs are shown in figure 7, which shows a rather large burr of $700 \mu \mathrm{m}$ height (a) and another of $50 \mu \mathrm{m}(\mathrm{b})$. Notice that the (a) view has homogeneous horizontal and vertical scales (zMag=1) whereas the (b) view has the $\mathrm{z}$-scale increased (zMag=5) in order to better show the burr details.

\subsection{Limitations}

Basically multifocus 3D microscopy fails in absence of a textured surface. Thus, blank objects like crystalline or finely polished surfaces cannot be measured and related difficulties appear in absence of local contrast that can appear also in specific locations as shown in figure 8. Raw metallic surfaces are usually wells suited as they show a quite favorable structured surface.
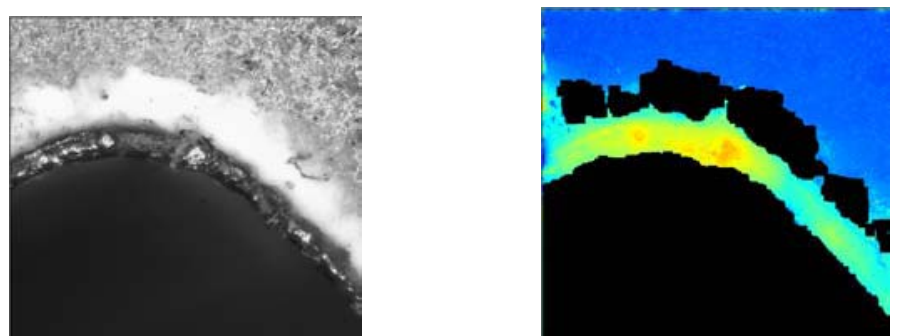

(a) Image $\quad$ (b) Depth map with undefined region

Figure 8: Example of metallic part with partial absence of contrast

\subsection{Conclusion}

Multifocus 3D microscopy was successful for the measurement of various kinds and dimensions of burrs in the submillimeter range. Burrs down to $10 \mu \mathrm{m}$ in size can be measured by normal means and burrs down to $5 \mu \mathrm{m}$ could be measured provided some noise reduction algorithm is applied. A full range image can be acquired in typically few seconds but there is potential for further speed up.

\section{CONCLUSIONS}

This paper considered multifocus 3D microscopy as a possible method for measuring 3D objects in the sub-millimeter range. Comparisons with other non-contact and fast methods: chromatic aberation, confocal microscopy and white light interferometry showed general advantages of accuracy for the later but a clear advantage of price for the multifocus 3D microscopy. Regarding speed, multifocus 3D microscopy is equal or better in performance and has potential for further speed up.

The accuracy is best derived from depth of field and has the property to be intrinsically bound to magnification. Practically, the rough accuracy is under two microns for larger magnifications and below $10 \mu \mathrm{m}$ for magnifications larger then 5.

The wood measurement applications showed that multifocus 3D microscopy is in a position to measure wood samples for further topographic analysis.

Multifocus 3D microscopy was successful for the measurement of various kinds and dimensions of burrs in the submillimeter range. Burrs down to $10 \mu \mathrm{m}$ in size can be measured by normal means and burrs down to $5 \mu \mathrm{m}$ could be measured provided some noise reduction algorithm is applied. A full range image can be acquired in typically few seconds but there is potential for further speed up. 


\section{ACKNOWLEDGMENT}

Part of the work presented in this paper was supported by the KTI/CTI Swiss Innovation Promotion Agency under project number E!2409 and 6007.1 KTS. The authors would like to thank Mr. E. Bachmann, S. Kohler and F. Vogel, for their collaboration and support.

\section{REFERENCES}

1. Grossmann P., Depth from focus, Pattern recognition Letters, 5 (1): 63-69, January 1987.

2. Nayar S. K., Watanabe M., and Noguchi M., Real-time focus range sensor, IEEE Transactions on Pattern Analysis and Machine Intelligence 18 (12): 1186-1198, DEC 1996.

3. Nayar S. K. and Nakagawa Y., Shape from focus, IEEE Transactions on Pattern Analysis and Machine Intelligence, 16 (8): 824-831 AUG 1994.

4. Robeneck H., Mikroskopie in Forschung und Praxis, GIT Verlag, 1995.

5. Ens J. E., An investigation of methods for determining depth from focus, PhD thesis, University of British Columbia, 1990.

6. Dickerson J. A., Robust calculation of the 2 nd derivative, URL http://www.eng.iastate.edu/ee528/sonkamaterial/chapter_4_3.htm.

7. Brändle N., Grundlagen der digitalen Bildanalyse Uebungsaufgaben, Teil 2, May 2002. URL http://www.prip.tuwien.ac.at/GdBALU/LUTeil2.pdf.

8. Allegro S., Chanel C., and Jacot J., Autofocus for automated microassembly under a microscope, 1996.

9. Sung-Lim K., Development of burr measurement system using laser and main application, 6th International Conference, Precision Surface Finishing and Deburring Dechnology, pp. 109..123, September 2000.

10. Leica, Leica microsystems, URL http://www.leica-microsystems.ch.

11. Stout K., Development of Methods for the Characterisation of Roughness in Three Dimensions, Kogan Page Science, 2000. URL http://www.koganpagescience.com/asp/ bookdetails.asp?key=3057.

12. Dornfeld D., Intelligent deburring of precision components, 3rd International Conference on Precision Surface Finishing and Burr Technology, pp. 25..38, November 1994.

13. Stango R., Cheng L., and Cariapa V., Automated deburring with a lamentary brush: Prescribed burr geometry, Journal of Manufacturing Science and Engineering 121, pp. 385... 392, August 1999.

14. Gillespie L. K., Inspecting for burrs, 5th International Deburring and Surface Finishing Conference, pp. 1..35, September 1998.

15. Pentland AP, A New Sense for Depth of Field, IEEE Transactions on Pattern Analysis and Machine Intelligence 9 (4): 523-531 JUL 1987.

16. Murali Subbarao, Tae Choi, Focusing techniques, Optical Engineering 32 (11):2824-2836 NOV 1993.

17. Matrox Imaging Library, http://www.matrox.com

18. Open Computer Vision Library: a collection of algorithms and sample code for various computer vision problems http://sourceforge.net/projects/opencvlibrary/

19. INTEL Image Processing Library 2.5 Reference Manual, Document Number 663791-005, 2000. http://www.intel.com/support/performancetools/libraries/ipl/ 